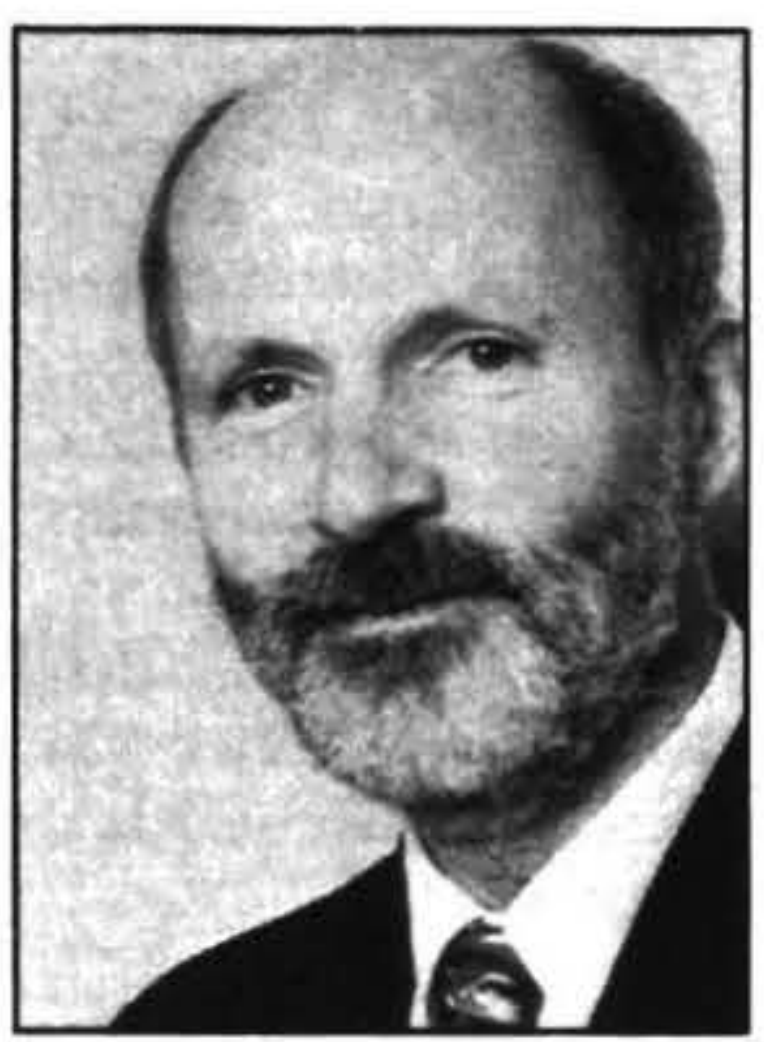

\title{
LABOUR MARKET STATISTICS - PLUGGING THE GAPS
}

\author{
Ian Ewing and Sharon Evans
}

\author{
Statistics New Zealand
}

\begin{abstract}
Official statistics have not kept pace with the deregulation of the labour market in the 1990 s. Beginning in 1992 with the 'Rose Review' there have been several assessments of the gaps and what is required to plug them. The report of the Prime Ministerial Task Force on Employment in 1994 and the 1996 work of an interdepartmental working group reached similar conclusions about the needs. In the last two years some important advances have occurred. The 1996 Census of Population extended the coverage of education and training topics. Central government funding was obtained for Household Labour Force Survey supplements on education and training (once only) and income (annually). Results from all three supplements will be available in 1997. Feasibility studies, funded by a group of Government agencies, have been done on employer's training practices and expenditure. Statistics New Zealand has developed new classifications for levels of educational attainment and field of educational study. There are still a number of unmet needs, particularly in the areas of labour market dynamics, workplace industrial relations, employment-related business statistics and Maori labour force involvement. Options for funding these have been explored in 1996 with no positive outcomes yet.
\end{abstract}

This paper begins by identifying the questions asked about the labour market and then discusses the information neededto answer them. The extent to which Statistics New Zealand has been able to meet identified needs is then explored. The paper also touches on aspects of the quality of the data sought, especially the frequency with which it is needed.

The adequacy of existing statistics are raised in the light of resource restrictions on planned improvements by Statistics New Zealand and the need to set priorities in a period of increasing resource constraints.

\section{What are the questions we seek to ask about the labour market?}

As with most markets the central questions relate to the efficiency with which the market works, the fairness of the outcomes it delivers, and the success of public policy interventions in the market.

The key questions include: the imbalances between labour supply and demand and their possible causes, the productivity of paid labour, and how fully labour resources are utilised. We also ask about the form relationships between employer and employee take, the accessibility and security of paid employment and income from employment is distributed. Associated with these are questions about the extent and value of unpaid work, whether working conditions are safe and healthy and the effectiveness of policy interventions.

A series of issues arising from these questions will serve as a framework for discussing data requirements. Consider first the question on productivity levels and whether they are rising or falling. Information is needed about the volume of labour inputs related to output volumes in a way which allows the productive contribution of labour and other factors (land, capital) to be separated. This information should be available for analysis by industry and sector. However, methodological difficulties remain for measuring productivity in the non-market sectors (e.g. non-profit and government services in New Zealand) and this has limited research on this question.

In order to understand how labour is utilised and the relationships with capital, we need information about the labour force status, hours worked, industry, occupation, qualifications and skills, and location of the working age population. In addition we need information on labour and employer organisation, contracting and bargaining practices, on the impact of work stoppages, and labour costs (including all forms of remuneration). Information on un-met demand, skill availability, and on labour turnover needs to be complemented with information about contracts: their coverage, terms, analysis by industry, sector, geography and firm-size.

In order to monitor access to paid employment and job security, we need information linking labour force status and duration of employment to demographic and social factors such as age, sex, ethnicity, occupation, skills and qualifications, location, family structure. These in turn need to be linked to information on non-standard forms of work (e.g. permanent, temporary, shift, night only etc).

Analysing trends in income and its distribution requires the linking of individual remuneration (both cash and in kind) 
to employment status and duration and to a similar mix of demographic and social factors. Further data requirements are needed to adjust nominal incomes for price increases, tax and benefit cahnges to measure change in the level of real disposable income.

In addition to the above we also need further information on unpaid work, the time involved by those who do it, their employment status, their involvement in paid work, their income and demographic and social characteristics. We also need data on the split between the time spent in contributing to market related outputs (e.g. unpaid assistance in a business or farm) or in providing non-market services (e.g. in the household or non-profit organisations serving households). There is also a need to develop robust measures of the value of unpaid work to assess its economic value.

Workplace safety and health issues pose their own set of data collection issues beginning with clarity of definitions - i.e. what constitutes an accident, and agreement on degrees of severity, use of internationally agreed classifications and consistent reporting. We need further information on the number and severity of workplace accidents and injuries, the time of day at which they occurred, and their economic impact, as well as details on the social and demographic characteristics of those affected. Information on hours worked, the safety of the workplace environment and contract terms and conditions are also required as they affect safety.

Associated with these substantive issues are those of quality and comparability. Standard definitions and classifications - industry classification, occupation, geography - allow data to be integrated across data sources. International comparability requires particular attention to definitions, e.g. employment and unemployment, accidents. Integrated statistics required a Common Business Frame, some have common coding practices (Census/BD) but not the HLFS. In order to make data useful we must understand its limitations. Knowing levels of accuracy is important and these include sampling error (HLFS Maori and PI estimates), coverage (PES), sources of bias and non-sampling error, e.g. QES coverage (small employers, self-employed) as well as available documentation on sources and methods (QES: filled jobs, HLFS: persons).

A central issue in planning statistics is their frequency. The frequency with which statistics should be produced depends on the rate with which the phenomena being measured change, and the cost/benefit of measurement. Structural changes such as the demographic or ethnic make up of the labour force can be measured less frequently (say annually or five yearly) than say the rate of change in the level of employment (currently measured quarterly in New Zealand, but measured monthly in most OECD countries). In the case of studying productivity for example, information about changes in the real value of production are needed quarterly (i.e. quarterly GDP), whereas measures of labour productivity would probably be satisfactory of an annual basis.

Utilisation/relationships pose other questions about the tim- ing of coverage. In this case even small changes in labour force participation, employment and unemployment rates are significant signals of change in economic activity and therefore measurement at least quarterly is required. However, the added value of measuring quarterly changes in the age, sex, educational qualifications, ethnic or regional makeup of the labour force is open to question and therefore annual measures may have to be sufficient. Annual statistics on employment contract characteristics would normally be sufficient but if patterns were expected to remain stable then less frequent measurement may suffice.

Issues of accessibility to and security of employment relate to the structure of the labour force, and annual or even less frequent measures may well be sufficient. An added dimension is the measurement of changes as they affect individuals through time, which suggests a need for longitudinal data rather than a series of annual snapshots.

Incomes and their collection frequency poses yet other issues. Changes in the total level of income need to be measured quarterly, if the demand for real quarterly income based measure of GDP is to be met (though this could be derived from payments made to employees). The structural relationship between income, labour market participation and the factors which affect it can be measured annually or less frequently but also require longitudinal data. Income (both transfers and remuneration from employment) is required annually for nominal GDP measures, and because income changes tend to occur on an annual basis.

Unpaid work data should be available on a similar frequncy as that relating to paid work, to allow assessment of movement between paid and unpaid work. On the other hand, annual measures would be sufficient to track changes in safecy and health (improvements, deterioration, emergence of new problems)

Finally, policy interventions questions usually require adhoc data collection specifically designed to relate policy interventions to outcomes.

\section{How adequate are current official statistics and what improvements are planned?}

Physical measures of labour inputs include full and part-time employment numbers as measured in the Quarterly Employment Survey. The QES also provides hours worked, but only for a single reference period within each quarter, and does not distinguish full and part-time hours worked. The survey is also limited by coverage shortcomings. Information of hours worked in provided quarterly in the Household Labour Force Survey (HLFS) on the other hand, but at an aggregated industry level only, is only based on principal job, and industry coding is based on respondents' self-description. In addition the Quarterly Manufacturing Survey (QMS) provides quarterly estimates of hours worked in manufacturing industries.

Measures of output value are derived from surveys such as the Annual Enterprise Survey, Quarterly Manufacturing and 
Wholesale surveys, Monthly Retail, Quarterly Building Activity Survey. Producers Output Price indexes allow volume measures to be derived. The Annual Agriculture Survey provides physical measures of farming outputs. Tax based data (GST) provides a possible alternative/supplement to survey based data for quarterly output measurement.

There are currently no official labour productivity measures. To produce these the key data would require improved measures of physical labour inputs. A report by Dennis Rose in 1992 undertaken to identify shortcomings in Labour Market statistics recommended an economy-wide quarterly measure of labour inputs (hours worked were the preferred measure) (see the summary in Rose and Brown, 1993 and also Trewin, 1995).

Alternatively, some improvements in current data sources could allow periodic measures of actual hours worked to be used in combiation with information on full and part-time employment numbers to model input volumes.

There is also a need to develop physical output measure for non-market sector activities (government and PNPs). Statistics Canada has developed labour, capital and multifactor productivity measures and work is currently being undertaken in the Australian Bureau of Statistics to develop output measures for non-market sectors based on earlier work done in the United States. Apart from following overseas work, and some preliminary development of Capital Stock measures, little work has been done by Statistics New Zealand.

\section{Utilisation and efficiency}

The Annual Enterprise Survey provides annual labour input costs for most industries (except agriculture and core government services). Annual Central Government and Local Authority surveys provide similar data for those sectors. The Labour Cost Index provides measure of change in real labour costs quarterly. However, the index does not cover all forms of non-cash remuneration, nor does it include nonregular bonuses and other irregular payments).

There is limited sub-annual Labour input cost data. The Quarterly Employment Survey for example only provides single pay period salary, wage and one-off payments for each quarter and exlcludes significant industries such as agriculture, small employers and working proprietors. The hours however relate to hours paid for rather than hours worked. The Quarterly Manufacturing Survey provides quarterly salary and wages costs and hours worked data - but the quality is open to question - multiplies of 40! QUERY

Quarterly information on changes in the number of filled jobs are derived from the Quarterly Employment Survey is made available by industry, location, part and full-time status and by size of employing business and by region. Monthly statistics are available on the economic impact of work stoppages. Information available from the $1996 \mathrm{Cen}$ sus of Population will provide additional analysis of educational qualifications and current involvement in formal training, the results for which are due in February 1997. A one-off education and training supplement has been included in the HLFS in the September 1996 quarter, with results due in February 1997.

Feasibility studies have been undertaken to assess what data on training practices and expenditure on training can be collected from employers. There is scope for exploiting tax data (e.g. PAYE?) to provide labour cost/remuneration data on a sub-annual (monthly or quarterly) basis to supplement or replace survey data.

There is a need for consistent periodic data on skill shortages and projected demand. The disability survey undertaken as a follow up to the Census will include a question on labour force status, allowing disability to be related to employment and related variables, including Census variables.

\section{Access and Security}

HLFS provides quarterly information on lenght of time spent in periods of unemployment, not in labour force etc. It does not however provide data on job tenure that is whether jobs are permanent, temporary or casual.

The 1996 Household Disability Survey collected information relating to access/barriers to employment for people with disabilities, including for example of/unmet (QUERY) need for special equipment, modified hours/duties, building modifications, and transport to work.

Statistics New Zealand, with support from Treasury and the Social Policy Agency have put forward proposals for undertaking a longitudinal survey of labour and income dynamics both for FoRST and direct government funding but have not so far been successful in securing funds.

\section{Incomes}

Five yearly information from the Census of Population and Dwellings provides data on income within broad annual income classes, and from all sources for individuals. The Census also provides data on individuals' employment status as a the time of the Census as well as providng detailed personal and household demographic and social data. Family and Household structure data allows family and household income data to be derived.

Annual information is available on individual and household income and expenditure from the Household Economic Survey (HES) with associated employment information. Analysis of the data for population subgroups is limited by the small sample size of the HES, however by combining data from HES over more than one year, or with data from other sources (such as the Census or taxation) it may be possible to develop synthetic income estimates for population subgroups.

An annual income supplement is being developed for inclusion in the HLFS. It will be included in the June quarter and, subject to satisfactory testing, should provide data on recent income from employment and transfers as well as annual 
Annual information on the structure and distribution of earnings, via a firm based survey which collects additional data on occupation, age, qualifications and gender of employees is sought. This type of information is collected in other developed countries such as Australia, the UK and Canada.

Quarterly information on total employment costs are required to develop an income based measure of GDP. Taxation (PAYE) is a likely source for the salary and wage component.

As noted above, proposals for a longitudinal survey of labour and income dynamics have yet to secure funding and no adequate measure has yet been put in place to replace the Real Disposable Income index.

\section{Unpaid work}

Some information will be provided from the 1996 Census on the type and amount of unpaid work which individuals have done in a recent reference period both within their own household and in the wider voluntary sector. The question distinguishes market focusses from non-market focusses unpaid work.

Statistics New Zealand has just prepared a proposal to obtain funds to conduct a basic time use survey in New Zealand. The objective of the survey would be to provide [QUERY] which could be used as benchline information on how New Zealanders spend their time and the activities in which they participate.

The information from such survey would enhance current employment statistics and provide more comprehensive analysis of the factors which impact on people's ability to participate in the paid workforce, or to provide community and voluntary services.

Time use data would also allow a more accurate assessment of different econom QUERY Including only paid work in an analysis of productive activities produces an QUERY picture, particularly in those sectors where there is a high unremunerated QUERY or where there has been a transfer of activities between the market and non-market sectors.

Time use surveys provide more accurate data than is available from conventional QUERY on the actual hours of paid work people undertake and the times of day and QUERY which this work occurs.

\section{Safety and health}

The Occupational Safety and Health division of the Department of Labour maintains two databases; the notifiable Occupational Disease System and the Asbestos Register. Registration on these databases is voluntary and it is not possible to estimate the number of cases which are not reported.
The Accident Compensation Corporation's statistics division collects information about work related injuries by industry, occupation and whether or not these injuries were fatal. Not all accidents are reported, especially if no ACC claim is involved. There is limited information on non-work accidents.

Statistics New Zealand is currently involved in running the New Zealand Health Survey. The survey asks if any injuries or poisonings that occurred in the last twelve monhts happened in the workplace. The survey also collects age, sex and ethnicity, which may provide useful information in relation to accidents in the workplace.

\section{Policy specific collections}

These are designed specifically to measure the impact of policy initiatives. A good example is the longitudinal Survey of Employment and Unemployment Practices (SEUP) undertaken by the Australian Bureau of Statistics. The survey is designed to track respondents' employment experiences to determine whether their involvement in the scheme has made any difference to their employment and income prospects.

In New Zealand in 1992 and 1993 some supplementary questions were added to the quarterly employment survey to assess the impact of the Employment Contracts Act by collecting details of the coverage and nature of employment contracts. It is not clear that this data provided much added insight into the economic impact of the ECA.

\section{Statistics New Zealand's development priori- ties}

Several assessments of labour market statistics have been undertaken over the last five years or so. The Review of Macro-Economic Statistics (1991) argues that factor productivity measures be given level 1 priority and income based GDP measure, level 3 priority.

The Rose Report (1992) identified data needs but did not assign priorities. The needs identified included the structure and distribution of earnings, employment contracts, productivity, participation in educationand training, and employer spending on education and training. The report also argued for improved educational qualifications data, improved earnings statistics, a transition to work survey (youth cohort survey) and a longitudinal survey to study labour market dynamics as well as a time use survey.

The Prime Ministerial Task Force on Employment (1994) covered slightly different areas but again offered no clear priorities. They listed participation in education and training-link to employment outcomes, information on employer investment in training, and improved timelness and detail of incomes data (through HLFS supplement). They also included firm based survey of occupational earnings, longitudinal data on labour and income dynamics, data on nonstandard work, improved regional data, and improved data 
on Maori and Pacific Island peoples.

The inter-departmental working group in 1996 was required to set priorities and consider funding options with respect to government SRAs [QUERY] and the contribution of new data to policy and research. In terms of statistics they argued for improved incomes statistics, skill development-education and training/participation and investment statistics, subgroup statistics (regional, Maori, Pacific Island people), better data on labour market and income dynamics, as well as non-standard work and new migrant participation in employment.

\section{Progress to date}

The following enhancements have been made:

- inclusion of a question on educational qualifications in the 1996 census

- inclusion of a question on unpaid work in the 1996 census

- questions on employment in the 1996 census consistent with HLFS

- Post Enumeration Survey to measure coverage of the 1996 census

- Household Disability Survey

- Household Health Survey

- HLFS Education and Training Supplement

- HLFS Annual Income Supplement

\section{Future developments}

These include the rebasing of the Household Survey Frame which is a Statistics New Zealand funding priority. There is a need to improve business based employment statistics so we can learn more about the earnings distribution across occupations, industries and regions by age and gender. These are necessary in order to overcome shortcomings in the QES coverage. Here we plan extended use of tax data but again is dependent on Statistics New Zealand funding approval.

There is a clear need to improve the analysis of subgroup statistics from the Household Labour Force Survey. Increases to the size of this survey is very expensive and alternatives have to be sought such as between expanding the survey size every two years but with some reduction in quality. A special post-censal survey might be considered here.

There is an ongoing need to improve out measurement of labour productivity. This is not funded at present and will require additional funding if it is to go ahead.

Income based GDP estimates are also desirable but no funding was provided in last year [1995?] and funding is currently being sought from principal users.

A longitudinal survey of labour and income dynamics is also planned but thus far the project has not been funded either by Government nor through FoRST. Similarly with the timeuse survey and the proposal will again be submitted to FoRST.

\section{References}

Trewin, D. 1995 Labour market statistics: a progress report and discussion. In Morrison, P.S. (ed) Labour, Employment and Work in New Zealand. Proceedings of the Sixth Conference. Victoria University of Wellington, 385-387.

Rose, D. and P. Brown 1993 Review of labour market statistics. In Morrison, P.S. (ed) 1993 Labour, employment and work in New Zealand. Proceedings of the Fifth Conference, Victoria University of Wellington. 156-169.

\section{Authors}

Ian Ewing is the Deputy Government Statistician and Sharon Evans is manager of Labour Market Statistics, Statistics New Zealand, PO Box 2922, Wellington 